\title{
UTILITARIAN PROBLEMS \\ UNDER THE CONTROL OF \\ ARTIFICIAL INTELLIGENCE
}

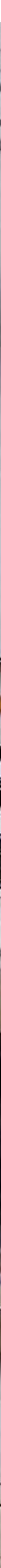


In the past decades, technology and IT activities have completely dominated the global job market. Virtual reality created by humans is no longer controlled by us as closely as by artificial intelligence (AI). Many algorithms perform a sequence of tasks to make human work as efficient as possible. Among the areas of their activity, ecological waste management deserves special attention, since it requires an interdisciplinary approach to ensure high efficiency of the flow of raw materials, semi-finished, and finished products from the place of consumption to the place of origin.

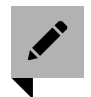

text: Katarzyna Stołpiec

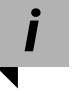

Krzysztof Szwarc, MSc Eng. Institute of Computer Science Faculty of Science and Technology University of Silesia krzysztof.szwarc@us.edu.pl
René Descartes, a French philosopher and mathematician who lived in the 17th century, predicted that in the future machines would be able to make decisions and function in the likeness of humans. From today's perspective, it is possible to argue that the thinker was right. Artificial intelligence has a huge amount of information at its disposal which it processes and gives to humans as a finished product made with a single mouse click. One example of the application of AI is its use as computational intelligence in reverse logistics, a very important and integral component that falls within the scope of ecology's interests.

Krzysztof Szwarc, MSc Eng., a doctoral student at the Institute of Computer Science at the University of Silesia in Katowice, deals on a daily basis with the application of computational intelligence methods in the process of solving various utilitarian problems, such as the interdisciplinary issue of planning mobile waste collection, which lies in the area of interest of reverse logistics.

"Due to artificial intelligence algorithms, it is possible to effectively construct a list of points from which old or used equipment should be picked up and to arrange all routes in such a way that time and kilometers are saved while every reported location is visited. Moreover, $\mathrm{CO}_{2}$ emission is reduced in correlation with the lesser distance to be covered," the scientist says.
Storage of electro-waste is a less popular method of waste management. The European Parliament alarms that, in many member states, electrical and electronic equipment is being recycled at less than $40 \%$. Poland's statistics are growing year by year, but it has still not been possible to surpass this relatively low threshold.

This type of waste is a growing problem around the world. The technology market, which continuously introduces new equipment, drives demand and consumption, at the same time affecting the growing amount of obsolete devices being discarded. Everyone likes to work on a new computer or smartphone that looks nice, is fast, and has been equipped with the latest applications that can improve our work or simply make its use more enjoyable. The attractiveness of new products is unfortunately one of the reasons why used equipment is replaced by newer models, although some of them are still functioning. Consumption is thus faster than product aging.

"When deciding to purchase new equipment, it is a good idea to keep social responsibility in mind and pay attention to the potential wastage of equipment or of the raw materials from which it is made. Unused equipment often ends up at the bottom of a drawer. From the ecological point of view, it seems more beneficial to e.g. resell unused electronics or to hand it over for specialized disposal, thus allowing for the recovery of some components that can be used further," says Krzysztof Szwarc, MSc Eng.

One of the solutions made possible by artificial intelligence is the use of metaheuristics to optimize the collection plan for the returned equipment. They take into account various constraints such as the vehicle fleet, travel time, as well as the entire loading and unloading procedure. After receiving the most important information, they are able to provide a precise solution which guarantees a high level of customer service.

"If the user is to be willing to hand over their old equipment to a specialist outlet, they must feel encouraged to do so," the doctoral student says. "A message about environmental protection is unfortunately not enough. Despite so many campaigns promoting an eco-friendly lifestyle, few people decide to use waste equipment in this way. To encourage them, mobile collections are organized, time windows are taken into account, and equipment can be collected."

As it turns out, artificial intelligence supports humans in proportion to their effort. Without the human factor, virtual space alone cannot meet all the expectations set by the contemporary world. Despite these dependencies, AI offers opportunities that, in turn, would be impossible without its participation. May the cooperation of human intelligence with AI bring benefits that will make this world a better and cleaner place. 